\title{
GRAIN GROWTH IN POLAR ICE: II. APPLICATION
}

\author{
By R. B. Alley, \\ (Geophysical and Polar Research Center, Department of Geology and Geophysics, \\ University of Wisconsin - Madison, Madison, Wisconsin 53706, U.S.A.) \\ J. H. PEREPEZKo, \\ (Department of Metallurgical and Mineral Engineering and Materials Science Program, \\ University of Wisconsin - Madison, Madison, Wisconsin 53706, U.S.A.) \\ and C. R. BENTLEY \\ (Geophysical and Polar Research Center, Department of Geology and Geophysics, \\ University of Wisconsin - Madison, Madison, Wisconsin 53706, U.S.A.)
}

\begin{abstract}
Grain growth observed in polar ice that is not deforming rapidly can be accounted for if concentrations and distributions of extrinsic materials (microparticles, bubbles, and dissolved impurities) are characterized fully. Dissolved impurities segregate to grain boundaries and slow grain growth in all cold glacial ice. The high concentration of soluble impurities in Wisconsinan ice from the Dome C (Antarctica) ice core (and perhaps other ice cores) probably causes the small grain-sizes observed in that ice. Microparticles have little effect on grain growth in ordinary ice. In ice layers that appear dirty owing to concentrations of volcanic tephra (such as in the Byrd Station (Antarctica) ice core) or of morainal material, microparticles reduce grain-growth rates significantly. The relatively high vapor pressure of ice allows rapid growth and high mobility of intergranular necks, so grain growth in firn is limited by boundary migration rather than by neck growth. Bubbles formed by pore close-off at the firn-ice transition are less mobile than grain boundaries, causing bubble-boundary separation whenever geometric constraints are satisfied; however, such separation reduces grain-growth rates by only about $10 \%$. The observed linear increase of grain area with time is thus predicted by theory, but the growth rate depends on soluble-impurity concentrations as well as on temperature.
\end{abstract}

RÉsumÉ. Croissance des grains dans la glace polaire: II. Applications. On peut rendre compte de la croissance des grains observée dans la glace polaire à déformation lente par une bonne description des concentrations et répartitions des matériaux extrinsèques (microparticules, bulles et impuretés dissoutes). Les impuretés dissoutes se rassemblent aux frontières des grains pour en diminuer la croissance dans toute glace froide. La forte concentration des impuretés solubles dans la glace du Wisconsin au Dome C (Antarctique), et peut être d'autres carottages, est la cause probable de la faible taille des grains observée dans ce type de glace. Les microparticules n'ont qu'un faible effet sur la croissance des grains pour de la glace ordinaire. Dans des couches de glace qui apparaissent sales par suite de la présence de téphras volcaniques (comme dans la carotte de glace de la Byrd Station, Antarctique) ou bien chargées en matériau morainique, les microparticules réduisent notablement les taux de croissance des grains. La relativement forte pression de vapeur de la glace permet une croissance rapide et une grande mobilité des appendices intergranulaires, de sorte que la croissance du grain dans le névê est limitée par les migrations à la frontière plutôt que par la croissance des appendices. Les bulles formées par le fermeture des pores lors de la transition névé-glace sont moins mobiles que les frontières des grains; en causant des frontières de séparation de bulles partout où les conditions géométriques sont satisfaites; cependant une telle séparation réduit la vitesse croissance des grains d'environ $10 \%$ seulement. La croissance linéaire observée de l'aire grains avec le temps est dans ces conditions prédite par la théorie, mais le taux de croissance dépend des impuretés solubles ainsi que de la température.

ZUSAMMENFASSUNG. Kornwachstum in polarem Eise: II. Anwendung. Das in polarem Eis, das sich nicht schnell verformt, beobachtete Kornwachstum kann erklärt werden, wenn die Konzentration und Verteilung eingelagerter Materialien (Mikropartikel, Blasen, gelöste Verunreinigungen) voll gekennzeichnet sind. Gelöste Verunreinigungen sondern sich von Korngrenzflăchen $a b$ und verzögern das Kornwachstum in kaltem Gletschereis. Die hohe Konzentration lösbarer Verunreinigungen in Eis aus der Wisconsin-Zeit vom Bohrkern aus Dome C (Antarktika) (und vielleicht auch aus anderen Eisbohrkernen) ist vermutlich der Grund für die geringen Korngrőssen, die in diesem Eis zu beobachten waren. Mikropartikel haben auf das Kornwachstum in gewöhnlichem Eis nur wenig Einfluss. In Eisschichten, die infolge der Konzentration von vulkanischer Asche (wie etwa im Eisbohrkern der Byrd-Station in Antarktika) oder von Morănenmaterial schmutzig erscheinen, verzögern Mikropartikel das Kornwachstum erheblich. Der relative hohe Dampfdruck im Eis erlaubt das schnelle Wachstum und die hohe Beweglichkeit von Verbindungen zwischen den Körnern, weshalb das Kornwachstum in Firn eher durch Grenzflăchenwanderungen als durch Verbindungswachstum begrenzt ist. Blasen, gebildet durch den Abschluss von Poren beim Übergang von Firn zu Eis, sind weniger beweglich als Korngrenzflăchen, wodurch immer dann, wenn die geometrischen Einschränkungen erfüllt sind, eine Trennung zwischen Blasen und Grenzflăchen verursacht wird; doch verringert solche Trennung die Kornwachstumsrate nur um etwa $10 \%$. Die beobachtete lineare Zunahme der Kornflächen mit der Zeit ist damit durch die Theorie erklärt, aber die Wachstumsrate hăngt ebenso von der Konzentration löslicher Verunreinigungen wie von der Temperatur ab. 


\section{INTRODUCTION}

Grain growth in polar ice that is not deforming rapidly has been characterized in a number of excellent empirical studies, but many of the observations are not yet fully explained by theory. Here we draw upon the theory developed in the preceding paper (Alley and others, 1986; hereafter identified as paper I) to explain these observations.

The major observations regarding grain growth that we seek to explain are (Gow and Williamson, 1976; Duval and Lorius, 1980):

(1) In post-Wisconsinan ice that is not "dirty-looking", the cross-sectional area of grains increases linearly with time. The rate of increase is about the same for deep firn as for ice at the same site.

(2) Grain-sizes are smaller in dirty-looking ice than in clean ice of the same age at the same site.

(3) Bubbles do not migrate with grain boundaries in ice.

(4) Grain-size decreases downward across the HoloceneWisconsinan boundary.

In the preceding paper we showed that the rate of grain growth depends on the intrinsic nature and geometry of grain boundaries in ice, and on the effects of extrinsic materials (microparticles, bubbles, and dissolved impurities). Here we will discuss each extrinsic material in turn as it relates to the observations listed above, and we will comment on the intrinsic nature and geometry of ice as needed.

\section{MICROPARTICLES}

Abundant experimental and theoretical evidence exists that inert second-phase particles with incoherent interfaces (microparticles) cause a drag force, $P_{\mathrm{p}}$, that opposes grain growth (Hellman and Hillert, 1975). As we showed in paper I (equation (25)), the ratio of this drag force to the intrinsic driving force for grain growth, $P_{1}$, is given for uniformly sized particles by

$$
\frac{P_{\mathrm{p}}}{P_{1}}=\frac{9 V_{\mathrm{p}} R}{4 r_{\mathrm{p}}}
$$

where $V_{\mathrm{p}}$ is the volume fraction of particles, $r_{\mathrm{p}}$ is the particle radius, and $R$ is the average grain radius. Notice that the ratio $P_{\mathrm{p}} / P_{1}$ is also the relative fractional reduction in driving force for grain growth, and thus in grain-growth rate caused by microparticles (paper I, equation (21)).

Equation (1) is illustrated in Figures 1 and 2, which show how the particle-drag force increases as volume fraction of particles increases and as particle radius decreases. (However, as noted in paper I, the drag force will not increase as rapidly as the volume fraction of particles if the volume fraction significantly exceeds about 1\%.)

As examples of the effect of microparticles on grain growth, consider data from the Devon Island Ice Cap of Arctic Canada (Koerner and Fisher, 1979) and from Dome C, East Antarctica (personal communication from E. MosleyThompson, 1985), two very different sites on polar ice caps. The data necessary to evaluate Equation (1) are listed in Table I, both for Wisconsinan and Holocene ice. For Dome $C$, we have taken complete particle-size analyses from typical Wisconsinan and Holocene samples, calculated the drag arising from particles in each size class, and summed these drags to give the total drag. The numbers in Table I are the measured volume fraction of particles and the weighted average particle radius that gives the calculated total drag. Koerner and Fisher (1979) did not report the particle-size distribution in Devon Island ice, but our assumed values of $r_{\mathrm{p}}$ in Table I are reasonable or over-estimate drag and concord with the data reported Equation (1) is evaluated in the final column of Table I.

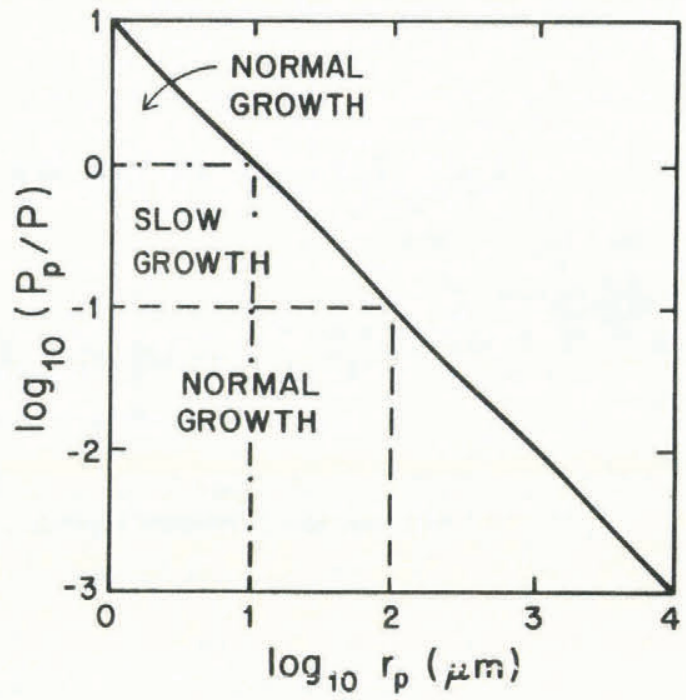

Fig. 1. Ratio of particle-drag force $\left(P_{p}\right)$ to driving force for boundary migration $(P)$ in ice as a function of microparticle radius $\left(r_{p}\right)$ for volume fraction of particles $V_{p}=0.01$ and average grain radius $R=4 / 9 \mathrm{~mm}$, calculated from Equation (1). Notice that $P_{p} / P$ is also the fractional reduction in grain-growth rate.

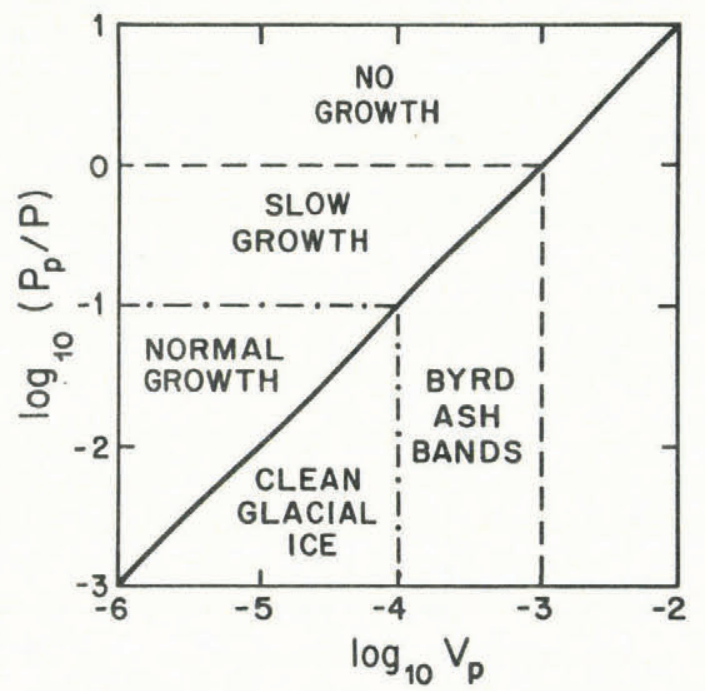

Fig. 2. Ratio of particle-drag force $\left(P_{p}\right)$ to driving force for boundary migration $(P)$ as a function of volume fraction of particles $\left(V_{p}\right)$ for particle radius $r=1 \mu \mathrm{m}$ and grain radius $R=4 / 9 \mathrm{~mm}$, calculated from Equation (1).

We have ignored Aitken particles in this analysis. (Particle distributions are typically bimodal (Shaw, 1979), with abundance peaks in the microparticle range, considered above, and in the smaller Aitken range.) Shaw (1979) suggested for the East Antarctic plateau that Aitken particles are primarily composed of sulfates that condensed in the free atmosphere, are about 1000 times more abundant numerically than larger particles, and have a modal radius of about $5 \mathrm{~nm}$. It is likely that the sulfate from many Aitken particles will dissolve in ice. If no Aitken particles dissolve, however, they will cause an order of magnitude less drag than larger particles at Dome $\mathrm{C}$, and thus can be ignored. Then even if our estimates of the effects of microparticles are low by a full order of magnitude, grain growth is still slowed by less than $2 \%$ at both sites and falls well within the "normal growth" regions of Figures 1 and 2 .

It was observed by Koerner and Fisher (1979) that the downward decrease in grain-size across the HoloceneWisconsinan boundary correlates strongly at several polar 

POLAR ICE

\begin{tabular}{|c|c|c|c|c|c|}
\hline Site & Sample & $\begin{array}{l}r_{\mathrm{p}} \\
\mu \mathrm{m}\end{array}$ & & $V_{p}$ & $\begin{array}{c}R \\
\mathrm{~mm}\end{array}$ \\
\hline $\begin{array}{l}\text { Dome C, } \\
\text { Antarctica }\end{array}$ & $\begin{array}{l}\text { Wisconsinan } \\
\text { Holocene }\end{array}$ & $\begin{array}{l}0.5 \\
0.5\end{array}$ & $\begin{array}{l}0.98 \\
0.10\end{array}$ & $\begin{array}{l}\times 10^{-7} \\
\times 10^{-7}\end{array}$ & $\begin{array}{l}0.9 \\
2.5\end{array}$ \\
\hline Devon Island & $\begin{array}{l}\text { Wisconsinan } \\
\text { Holocene }\end{array}$ & $\begin{array}{l}2.0 \\
1.0\end{array}$ & $\begin{array}{r}17.10 \\
0.30\end{array}$ & $\begin{array}{l}\times 10^{-7} \\
\times 10^{-7}\end{array}$ & $\begin{array}{l}0.8 \\
1.1\end{array}$ \\
\hline Byrd Station, & D usty layer & 4.0 & 1900 & $\times 10^{-7}$ & 1.0 \\
\hline
\end{tabular}

The modal microparticle radius is designated $r_{\mathrm{p}}$, the volume fraction of microparticles $V_{\mathrm{p}}$, the grain radius $R$, and the ratio of particle-drag force to driving force for grain growth $P_{p}^{\prime} / P_{1}$. Notice that $P_{\mathrm{p}} / P_{1}(\%)$ is also the percentage reduction in grain-growth rate caused by microparticles.

sites with an increase in microparticle concentrations across the same boundary. In the light of the known effect of microparticles on grain growth, Koerner and Fisher (1979) advanced the reasonable hypothesis that the high concentrations of microparticles in Wisconsinan ice cause the small grain-sizes observed there. From Table I it is clear, however, that this hypothesis cannot be correct. (Duval and Lorius (1980) reached this same conclusion using a slightly different form of Equation (1).)

In layers rich in morainal material or volcanic ash or dust, however, microparticles may be sufficiently concentrated to affect the grain-growth rate significantly (Gow and Williamson, 1976; Koerner and Fisher, 1979). In the Byrd Station (Antarctica) ice core, layers rich in volcanic dust and ash can be identified visually as fine-grained dirty ice, and high concentrations of volcanic tephra occur only in such dirty-looking ice (Gow and Williamson, 1976). For the dust layer from $1412.3 \mathrm{~m}$ depth in the Byrd Station core, Kyle and others (1982) reported a unimodal distribution of particle sizes with the modal radius and concentration listed in Table I. Estimating the grain-size from Gow and Williamson (1976) and assuming that all particles have the same modal radius, we calculate that microparticles reduce grain-growth rates by about $11 \%$ in this layer. This is a typical dust layer, and many dust layers probably have higher concentrations of microparticles than this one. Grain growth in the Byrd Station core is complicated, and is probably affected by disssolved impurities (see below) and by deformation of the ice (Gow and Williamson, 1976). Although the effect of microparticles is not large enough by itself to cause the small grain-sizes that are observed in the ash- and dust-rich layers, particles can have a significant effect on grain growth in these layers and must be considered.

Thus, in ordinary, clean glacial ice microparticles have little or no effect on grain growth. Only in ice that appears dirty do microparticles slow grain growth significantly. The observed inverse correlation between grain-size and microparticle concentration in Wisconsinan versus Holocene ice is not a causal relation.

\section{BUBBLE DRAG}

The similarity of grain-growth rates in isothermal firn and ice at a given site (Gow, 1970) is striking. Duval (1984) interpreted this to indicate that porosity is more mobile than boundaries in firn and so causes little drag, and that the observed bubble-boundary separation in ice does not reduce the driving force for grain growth significantly. Here we confirm these suggestions quantitatively, and we show that geometric factors plus the high vapor pressure of ice control bubble effects on grain growth.

First, consider bubble-boundary separation in ice. In paper I (equation (29)), we developed an expression for the maximum steady-state velocity of a bubble on a boundary between two grains. Using data for bubbles at pore closeoff at Byrd Station (Table I; Gow, 1968; Gow and Williamson, 1976), we calculate the maximum bubble velocity to be about $3.7 \times 10^{-4} \mathrm{~mm} \mathrm{a}^{-1}$ (Gow, 1970). This compares with an average grain-boundary velocity of about $1.4 \times 10^{-3} \mathrm{~mm} \mathrm{a}^{-1}$ (Gow, 1970), and so we predict bubbleboundary separation. Similar calculations indicate that boundary velocity also exceeds maximum bubble velocity in deeper ice at Byrd Station.

The bubble-drag theory developed in paper I assumes that bubbles are uniformly distributed in the ice and that bubbles are significantly smaller and more numerous than grains. However, Gow (1970) showed that, at pore close-off, there are only about as many bubbles as grains per unit volume, most bubbles lie on junctions of three or more grains, and many bubbles are cylindrical with one dimension long compared to grain-size. Grain growth and bubble compression with increasing depth cause ice to correspond more closely to the assumptions of the bubble-drag theory in paper I; however, for shallow ice we must estimate the bubble drag in a different manner. Two such estimates are presented below. Neither provides a full treatment of bubble drag in shallow ice, and further theoretical work is warranted, but both indicate that bubble drag reduces grain-growth rate by only about $10 \%$.

Bubbles at junctions of three grains cause less drag than bubbles on two-grain boundaries (Hellman and Hillert, 1975), both because separation of one boundary from a bubble at a three-grain junction requires little creation of new boundary, and because adjustment of the many threegrain junctions that lack bubbles allows much grain growth without requiring any bubble-boundary separation. Thus, although the bubbles at pore close-off at Byrd Station would reduce the grain-growth rate by about $50 \%$ according to Equation (1), actual reduction may be as little as $5 \%$.

Bubble drag in ice then should arise mainly from separation of bubbles from two-grain boundaries following isolation of bubbles on two-grain boundaries. Such isolation of a bubble on a two-grain boundary is impossible if the cross-sectional area of the bubble is larger than the boundary, however. Hsueh and others (1982) estimated that this geometric constraint prohibits bubble-boundary separation until $r / R<0.44$, where $r$ and $R$ are the bubble and grain radii, respectively. This condition is realized for average bubbles and grains at Byrd Station just below the firn-ice transition, but is not realized for some bubbles until somewhat deeper. Depending on local geometry, isolation of a bubble on a two-grain boundary and then bubble-boundary separation may occur immediately after the bubble becomes smaller than the boundary or only after an extended time. We thus expect bubble-boundary separation to begin at pore close-off but to continue over a large 
depth interval. Examination of thin sections from Byrd Station (Gow, 1968; Gow and Williamson, 1976) shows that all bubbles form on grain boundaries at pore close-off, that some bubbles separate almost immediately, but that the concentration of bubbles on boundaries exceeds that expected for a random distribution until about $250 \mathrm{~m}$ depth; thus, bubble-boundary separation occurs between about 65 and $250 \mathrm{~m}$.

We now use this observation to calculate the drag arising from bubble-boundary separation at Byrd Station. The force driving grain growth arises from the decrease in grain-boundary area and energy that results from grain growth, and the bubble-drag force arises from the increase in grain-boundary area and energy that results from bubbleboundary separation. Over some depth interval, the ratio of the boundary area per unit volume created by separation, $\Delta S_{\mathrm{s}}$, to the boundary area destroyed by grain growth, $\Delta S_{\mathrm{g}}$, then gives the relative magnitude of the bubble-drag force in that interval.

We can write

$$
\Delta S_{\mathrm{S}}=\pi \vec{r}^{2} n_{\mathrm{S}}
$$

where $\bar{r}$ is the average radius of bubbles separating from boundaries in the region and $n_{\mathrm{s}}$ is the number of bubbles per unit volume separating. Bubble radii at the beginning and end of bubble separation at Byrd Station from Gow $(1968,1970)$ are given in Table II; the average bubble radius at separation is about $\bar{r}=0.3 \mathrm{~mm}$. Although a few

TABLE II. DATA ON BUBBLES AT BYRD STATION, ANTARCTICA

$\begin{array}{ccc}\begin{array}{c}\text { Depth } \\ \mathrm{m}\end{array} & \begin{array}{c}\text { Bubble radius } \\ \mathrm{mm}\end{array} & \begin{array}{c}\text { Grain radius } \\ \mathrm{mm}\end{array} \\ 65 & & \\ 250 & 0.475 & 1.1 \\ & 0.168 & 2.3\end{array}$

bubbles may separate from one boundary, and then intersect and separate from a second boundary above $250 \mathrm{~m}$ depth, most only undergo a single separation in this depth region. The few bubbles that undergo multiple separations are probably balanced by a few that never separate in this region, and it is reasonable to assume that each bubble in a given volume of ice at Byrd Station separates from a boundary once between $65 \mathrm{~m}$ and $250 \mathrm{~m}$ depth. The concentration of bubbles at Byrd Station is remarkably constan with depth at $n_{\mathrm{S}}=2.2 \times 10^{8} \mathrm{~m}^{-3}$ (Gow, 1968). Substituting for $\bar{r}$ and $n_{\mathrm{s}}$ in Equation (2) yields

$$
\Delta S_{\mathrm{S}}=62 \mathrm{~m}^{2} / \mathrm{m}^{3} .
$$

(This is also essentially the same result we obtain if we assume that the time-rate of bubble separation is constant between $65 \mathrm{~m}$ and $250 \mathrm{~m}$ and use bubble-size data from different depth intervals between $65 \mathrm{~m}$ and $250 \mathrm{~m}$ to calculate the total boundary area created by separation.)

The grain-boundary area at any depth, $S_{g}$, is the boundary area per grain divided by the volume per grain. Noting that the boundary area per grain is $2 \pi R^{2}$ where $R$ is the grain radius (the other $2 \pi R^{2}$ of surface area of a spherical grain is assigned to adjacent grains) we find

$$
\begin{aligned}
S_{\mathrm{g}} & =\frac{2 \pi R^{2}}{\frac{4}{3} \pi R^{3}}, \\
S_{\mathrm{g}} & =\frac{3}{2 R} .
\end{aligned}
$$

This leads to

$$
\Delta S_{\mathrm{g}}=\frac{3}{2}\left(\frac{1}{R_{1}}-\frac{1}{R_{2}}\right)
$$

where $R_{1}$ and $R_{2}$ are the grain radii at the beginning and end of the depth interval of interest. Taking $R_{1}$ and $R_{2}$ from Table II for $65 \mathrm{~m}$ and $250 \mathrm{~m}$ at Byrd Station, we calculate

$$
\Delta S_{\mathrm{g}}=711 \mathrm{~m}^{2} / \mathrm{m}^{3} \text {. }
$$

We then calculate

$$
\left[\frac{\Delta S_{\mathrm{S}}}{\Delta S_{\mathrm{g}}}\right] \times 100=8.7 \%
$$

and the driving force for grain growth and the grain-growth rate are reduced by slightly less than $10 \%$ by bubbles at Byrd Station between $65 \mathrm{~m}$ and $250 \mathrm{~m}$ depth.

A second estimate of bubble drag in shallow ice comes from the observation that there are about as many bubbles as grains just below pore close-off (Gow, 1968). Suppose that each bubble prevents one grain boundary from migrating, which is equivalent to all bubbles occurring on twograin boundaries that lack sufficient driving force to escape bubbles and so are pinned. Grains are approximated by 14-faced tetrakaidecahedra (Coble, 1961). If each bubble pins a face shared by two grains, then two faces per grain are pinned and 12 are free to migrate, which should reduce the grain-growth rate by a factor of $2 / 14$, or about $14 \%$. Because the pinned faces can actually migrate in the lowvelocity regime (paper I), the reduction in grain-growth rate should be less than $14 \%$. Grain growth tends to increase the number of bubbles per grain, but some boundaries are observed to escape bubbles during grain growth, so the fraction of boundaries pinned by bubbles does not vary rapidly. It is true that for tetrakaidecahedral grains and one bubble per grain, about $40 \%$ of faces are contacted by bubbles if all bubbles occur at three-grain junctions and about $60 \%$ of faces are contacted if all bubbles occur at four-grain junctions; however, from Hellman and Hillert (1975) we know that a boundary is restrained less by a bubble at its side or corner than by a bubble in its center. It is thus reasonable to assume that each bubble pins one boundary, and that bubbles slow grain growth in shallow ice by about $10 \%$.

We thus see that both changes in surface area during grain growth and considerations of boundary pinning by bubbles indicate that bubbles in shallow ice slow grain growth on the order of $10 \%$. With increasing depth, growth of grains and compression of bubbles cause the geometry to resemble more closely that used in paper I to calculate the bubble drag. Below $250 \mathrm{~m}$ at Byrd Station, that bubble-drag theory (Equation (1) in this paper) also yields a reduction in grain-growth rate of about $10 \%$. A $10 \%$ reduction in growth rate would be largely masked by natural variability and measurement errors, so we predict that bubble drag has little measurable effect on grain growth in ice. (However, should excess bubbles be introduced into a sample in some fashion, then we predict that bubble drag would reduce the grain-growth rate significantly.)

If bubble drag has little effect on grain growth in ice and growth rates do not change from firn to ice (Duval, 1984), then we might expect that porosity has little effect on grain growth in firn. The following analysis shows that this is the case.

Grain growth in materials with continuous porosity has received little attention. In a pioneering study, Greskovich and Lay (1972) considered grain growth in alumina during initial-state sintering. They concluded that necks between grains pin grain boundaries, that neck growth eventually allows boundaries to escape necks, and that boundary migration is much faster than neck growth; thus, grain growth in low-density alumina differs from the intrinsic case because it is limited by neck growth rather than by boundary migration.

The vapor pressure of ice is much higher than that of alumina at the same relative temperature (Weast, 1973, p D158, D162), which has two effects on grain growth in firn. First, it allows rapid neck growth. Our observations show that the ratio of average bond radius to average grain radius reaches 0.6 or greater in the upper $5 \mathrm{~m}$ of firn on 
the Siple Coast of West Antarctica and in central Greenland, and remains relatively constant in deeper firn; examination of published data (Gow, 1968, 1974) and calculations indicate that these observations hold true for all polar firn, although the precise rate of neck growth with depth depends on temperature, accumulation rate, and vapor flux down temperature gradients in shallow firn. A neck radius : grain radius ratio of 0.6 is relatively large, if it is remembered that the neck between a large and a smal grain is limited to the size of the small grain but that their average grain radius reflects both grains. Secondly, the high vapor pressure of ice allows necks to be highly mobile. In paper I (equation (29)), we showed that the maximum velocity of a bubble at atmospheric pressure is proportional to $1 / r^{2}$, where $r$ is the bubble radius, and that the drag force per bubble in the low-velocity regime is proportiona to $r^{3}$ (paper I, equation (31)). The air occupying the constricted region around a neck can be viewed as an odd-shaped bubble. We used equation (29) in paper I above to calculate that a bubble of radius $0.5 \mathrm{~mm}$ at Byrd Station has a maximum velocity of only about $1 / 4$ of the average boundary velocity. A typical neck has a depth of about $0.05 \mathrm{~mm}$ or less relative to the smaller adjacent grain. (A boundary migrates towards the smaller adjacent grain, so neck depth in that direction is the relevant physical parameter.) From equation (29) in paper I, the maximum neck velocity is then in excess of 25 times the average boundary velocity, so that little drag results.

Thus, the high vapor pressure of ice allows necks to grow rapidly and to exhibit high mobility, so that grain growth in firn is limited by boundary migration rather than by neck growth and is essentially intrinsic in behavior. Because we also have shown that grain growth in ice is nearly unaffected by porosity, we would predict similar growth rates in firn and ice; agreement between theory and observations is excellent.

\section{IMPURITY DRAG}

Abundant evidence from metallurgical systems shows that a soluble impurity will dissolve in a solvent lattice, segregate to grain boundaries, and decrease grain-growth rates significantly even at low concentrations. Classic empirical studies of impurity drag in metals were conducted by Aust and Rutter (1959) and Rutter and Aust (1960) for additions of small concentrations of tin, silver, and gold to high-purity lead. They found that:

(1) Migration of high-angle boundaries (boundaries across which there is large mismatch of lattice orientations) is slowed significantly by impurities, and the effect is nearly independent of relative orientation between grains, although special boundaries (boundaries across which there is little mismatch of lattice orientations, i.e. low-angle boundaries, and boundaries with high densities of coincident sites) are not affected strongly by impurity drag.

(2) The drag effect of impurities increases as the relative temperature decreases (here the relative temperature is defined as the absolute temperature of a system divided by the absolute temperature at which the pure solvent phase melts).

(3) The drag effect of impurities increases as the size difference and charge difference increase between the solute and solvent atoms. Partitioning of solute atoms to grain boundaries also increases with these factors. Thus, the impurity drag increases as the partition coefficient of the impurity to the grain boundary (the impurity concentration in the boundary divided by the impurity concentration in the lattice) increases.

(4) At a relative temperature of about 0.8 , the addition of 190 atomic parts per billion of silver to high-purity lead lowers the grain-boundary velocity by a full order of magnitude relative to the same lead without silver for a given driving force. The partition coefficient of silver to liquid lead during solidification of a dilute solution of silver in lead is about 25 .
Although further data are needed, excellent evidence is available that soluble impurities occurring in cold ice at very low concentrations do dissolve in the ice lattice, segregate to grain boundaries, and slow grain growth. In most of these studies, $\mathrm{NaCl}$ was examined as the soluble impurity.

In the laboratory, segregation of $\mathrm{Na}^{+}$to grain boundaries was detected by autoradiography by Mizuno and Kuroiwa (1970) in ice grown from a solution containing only 0.6 molecular parts per billion of the impurity ${ }^{22} \mathrm{NaCl}$. Chloride segregation to grain boundaries was observed in natural hailstones from Colorado and Nebraska by Prodi and Nagamoto (1971); salinities were not reported, but must have been quite low.

Natural ice in cold glaciers also seems to exhibit segregation of soluble impurities to grain boundaries. The in-situ behavior of the d.c. conductivity of ice at the South Pole is consistent with segregation of impurities to grain boundaries and triple junctions (Wolff and Paren, 1984). Impurities involved probably include $\mathrm{H}_{2} \mathrm{SO}_{4}, \mathrm{HNO}_{3}$, and $\mathrm{HCl}$ as well as $\mathrm{NaCl}$. Nuclear-magnetic-resonance studies of ice from Dome $\mathrm{C}$ are also consistent with grain-boundary segregation (Ocampo and Klinger, 1983).

Laboratory experiments on grain growth in the ice $-\mathrm{NaCl}$ system were conducted by Jellinek and Gouda (1969) and Chatterjee and Jellinek (1971) at bulk salinities of 58 and 293 atomic parts per million. They found that increasing salinity speeds grain growth above $-10^{\circ} \mathrm{C}$ but slows grain growth at lower temperatures. The acceleration of grain growth at high temperatures is caused by formation of a saline melt at grain boundaries. The slowing of growth by impurities at lower temperatures is the effect we expect based on impurity-drag theory.

We thus see that available data support the theoretical prediction that soluble impurities in cold ice will segregate to grain boundaries and reduce grain-growth rates significantly. Grain-size in dated ice cores records grain-growth rates, so we expect to find an inverse relation between grain-size and soluble-impurity content in ice cores. Examination of data from the French $905 \mathrm{~m}$ Dome C core supports this hypothesis.

The Dome $\mathrm{C}$ core is entirely in the depth region where grain growth is driven by the curvature of boundaries, and thus where our theories apply (Duval and Lliboutry, 1985). Extensive data have been collected from the core, including grain-size (Duval and Lorius, 1980), microparticle concentrations (Petit and others, 1981; Thompson and others, 1981), and impurity concentrations (Petit and others, 1981; Delmas and others, 1982). Much effort has also been devoted to establishing a time-scale for the core (Lorius and others, 1979; Bolzan, 1984). The data show that concentrations of microparticles and impurities increase and grain-sizes decrease from Holocene to Wisconsinan ice.

Possible causes of reduced grain-sizes in Wisconsinan ice have been considered by Duval and Lorius (1980). They concluded that the small grain-sizes in Wisconsinan ice could not be explained by changes over time in grain-sizes at the surface, by changes in growth temperature, or by the observed changes in microparticle concentrations (see section on microparticles, above). They speculated on the possibility that Wisconsinan ice may have greater preferred orientation of crystallographic axes than Holocene ice, and that this orientation might arise from some climatically induced change in near-surface processes. Parallel orientation of crystallographic axes would reduce surface tension between grains and thus reduce grain-growth rates.

Measurements of $c$-axis orientations have not been made on Wisconsinan ice from Dome $\mathrm{C}$ because the core is too fractured; however, four lines of evidence indicate that it does not contain strong $c$-axis textures. First, the Vostok core (from a site similar to Dome $C$ ) exhibits a gradual clustering of $c$-axes below the firn-ice transition, but no correlation of $c$-axis textures with the Wisconsinan-Holocene boundary. Strong $c$-axis textures do not develop until about $1000 \mathrm{~m}$ depth, much deeper than the Wisconsinan-Holocene boundary (Korotkevich and others, 1978). Secondly, the seismic experiments of Blankenship and others (1982) at Dome $\mathrm{C}$ are consistent with development of strong $c$-axis textures only below $1000 \mathrm{~m}$ depth at Dome C, well below 
the Wisconsinan-Holocene boundary. Thirdly, results of sonic logging of the Dome $\mathrm{C}$ hole are not consistent with strong $c$-axis textures anywhere along its length (personal communication from D. Blankenship, 1984). Finally, it is observed that $c$-axis textures do develop in near-surface regions today but are randomized during firnification (Nakawo, 1974). There does not seem to be any plausible mechanism by which glacial conditions would eliminate this randomization of $c$-axis orientations in firn.

We thus see that no previously proposed mechanism accounts for the small grain-sizes in Wisconsinan ice, and we proceed to develop our hypothesis that impurity drag is responsible. The data of Petit and others (1981) show that concentrations of $\mathrm{Na}^{+}$and $\mathrm{Cl}^{-}$increase about five-fold from Holocene to Wisconsinan ice. Concentrations of $\mathrm{HNO}_{3}$ and $\mathrm{H}_{2} \mathrm{SO}_{4}$ seem to follow this trend but with a lesspronounced change (Lorius and others, 1984); however, the signal of these acids is complicated by volcanic input and some sampling for these acids was conducted with regard to volcanogenic peaks (Delmas and others, 1982).

We will assume that $\mathrm{Cl}^{-}$is the impurity that controls grain-growth rates, and will calculate from data the grainboundary mobility in the absence of $\mathrm{Cl}^{-}$and the interaction parameter, $\alpha$, between $\mathrm{Cl}^{-}$and grain boundaries. $\left(\mathrm{Cl}^{-}\right.$in ice has a marine origin and is deposited on the ice sheet with marine $\mathrm{Na}^{+}$(Petit and others, 1981). Because $\mathrm{Na}^{+}$can also occur in insoluble form in terrigenous microparticles, we use $\mathrm{Cl}^{-}$to represent the soluble, marine impurities; however, it should be remembered that $\mathrm{Cl}^{-}$occurs with other marine impurities, mainly $\mathrm{Na}^{+}$, in their bulk marine ratios.) $\mathrm{By}$ using only $\mathrm{Cl}^{-}$in our calculations, we ignore many other impurities, including $\mathrm{H}_{2} \mathrm{SO}_{4}, \mathrm{HNO}_{3}, \mathrm{~N}_{2}$, etc. To evaluate the effects of ignoring these impurities, it is useful to consider three possibilities: (1) the concentration of some ignored impurity is proportional to the concentration of $\mathrm{Cl}^{-}$; (2) the concentration of some ignored impurity is independent of depth and thus of $\mathrm{Cl}^{-}$concentration; (3) the concentration of some ignored impurity varies with depth but is not proportional to the concentration of $\mathrm{Cl}^{-}$. If the first case is true, then we will calculate an effective interaction parameter, $\alpha$, that arises from $\mathrm{Cl}^{-}$and from other impurities, and it would be erroneous to assign it to $\mathrm{Cl}^{-}$only. $\mathrm{Na}^{+}$ and possibly volcanic acids are observed to vary directly with $\mathrm{Cl}^{-}$. If the second case is true, our calculated value of the grain-boundary mobility in the absence of $\mathrm{Cl}^{-}$will be the mobility of ice contaminated by the depth-invariant impurity rather than the mobility of pure ice. $\mathrm{N}_{2}$ and $\mathrm{O}_{2}$ may be such depth-invariant impurities. In these first two cases, we will not change the calculated form of the relation between grain-growth rate and impurity concentrations by ignoring some impurities. Only in the third case will our use of $\mathrm{Cl}^{-}$to represent all impurities lead to qualitatively erroneous conclusions. Available evidence indicates that the third case does not obtain for significant impurities at Dome $\mathrm{C}$ and other polar sites. $\left(\mathrm{CO}_{2}\right.$ does vary with depth and not in proportion to $\mathrm{Cl}^{-}$but, given its weak interaction with grain boundaries (Stauffer and Berner, 1978), it is unlikely that $\mathrm{CO}_{2}$ has a significant effect on grain-growth rates.)

Referring to the theory of impurity drag in the previous paper, we must next ask whether grain boundaries are saturated with $\mathrm{NaCl}$. The partition coefficients of $\mathrm{Na}^{+}$ and $\mathrm{Cl}^{-}$to liquid water from ice are about 3000 and 300 , respectively (Gross and others, 1975). We take the partition coefficient to grain boundaries to be 3000 , which should over-estimate the impurity concentration in grain boundaries. The bulk concentration of $\mathrm{NaCl}$ in ice from Dome $\mathrm{C}$ is about $10^{-7}$ molecular fraction or less (Petit and others, 1981 ), so the grain-boundary concentration is less than about $3 \times 10^{-4}$ molecular fraction $\mathrm{NaCl}$. The eutectic concentration of the $\mathrm{NaCl}-\mathrm{H}_{2} \mathrm{O}$ system is about 0.08 molecular fraction $\mathrm{NaCl}$ (Pounder, 1965); thus, grain boundaries in ice from Dome $\mathrm{C}$ are not saturated with $\mathrm{NaCl}$ and grainboundary thickness is constant at the value fixed by the intrinsic nature of ice.

Given this, we showed in paper I (equation (42)) that

$$
\frac{\mathrm{d} R}{\mathrm{~d} t}=\frac{32 \gamma / 81}{2 R\left(M_{\mathrm{i}}^{1}+\alpha C_{\ell}\right)}
$$

where $R$ is the average grain radius in a sample, $(\mathrm{d} R / \mathrm{d} t)$ is the rate of grain-boundary migration, $\gamma$ is the grainboundary energy, $M_{\mathrm{i}}^{-1}$ is the inverse of the intrinsic mobility, $C_{l}$ is the concentration of impurities in the lattice, $\alpha$ is the impurity/grain-boundary interaction parameter, and we have taken microparticle and bubble drags to be negligible. Because $C_{\boldsymbol{l}}$ is nearly independent of $R$ for the grain-sizes under consideration, this leads to

$$
R^{2}=R_{0}^{2}+K_{1} t
$$

where $R_{0}$ is the value of $R$ at time $t=0$ and $K_{1}$ is given by

$$
\frac{1}{K_{1}}=\frac{81}{32 \gamma}\left(M_{\mathrm{i}}^{-1}+\propto C_{1}\right) \text {. }
$$

The value of $R_{0}$ may vary slightly with climate; however, $R_{0}$ is generally sufficiently small that errors in its estimation are not significant. It is then possible to measure $R$ in a dated ice core and calculate $K_{1}$ from Equation (9). Because $\gamma$ is a known constant, Equation (10) then shows that a plot of $1 / K_{1}$ versus $C_{\ell}$ should be linear with intercept $\left(81 M_{\mathrm{i}}^{-1}\right) /(32 \gamma)$ and slope $(81 \alpha) /(32 \gamma)$.

Such a plot for Dome $\mathrm{C}$ is shown in Figure 3, along with the least-squares linear-regression line calculated

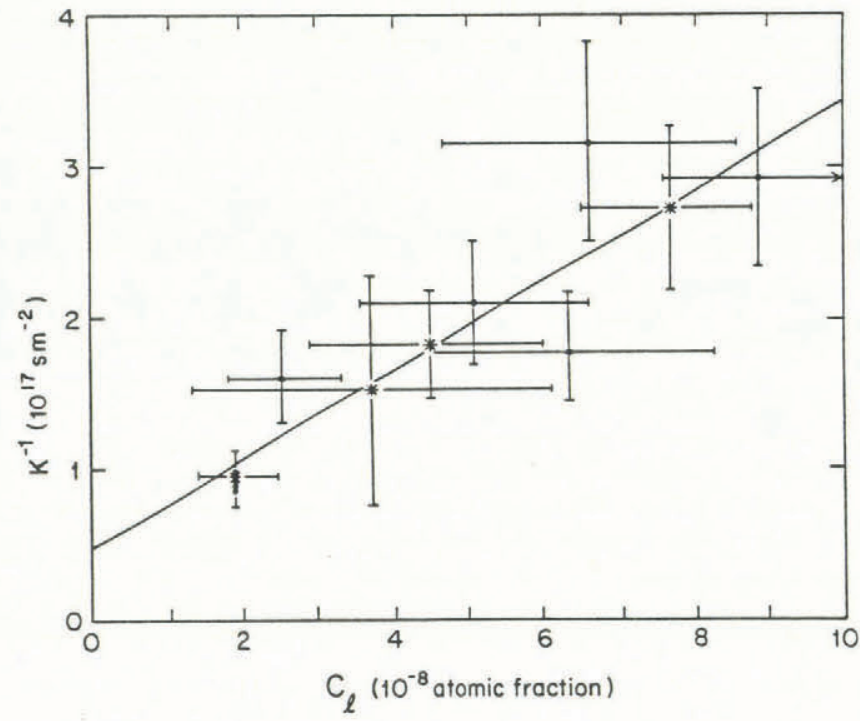

Fig. 3. Inverse of grain-growth-rate constant $\left(1 / K_{1}\right)$ from Duval and Lorius (1980) versus bulk concentration of chloride $\left(C_{\ell}\right)$ from Petit and others (1981) for ice from Dome C, East Antarctica. Solid circles ( $\bullet$ ) are values of $\left(1 / K_{1}\right)$ and $C_{1}$ interpolated to even multiples of $100 \mathrm{~m}$ depth, and stars (*) are averages over each of the four isotopic stages in the core discussed by Petit and others (1981). Error bars are discussed in the text.

assuming no errors in $C_{\boldsymbol{f}}$. Grain-size data are from Duval and Lorius (1980) and the time-scale is from Lorius and others (1979). The value of $R_{0}^{2}$ has been taken as $0.56 \mathrm{~mm}^{2}$. We used the bulk-concentration data of Petit and others (1981) for $\mathrm{Cl}^{-}$. Bulk concentration is essentially the same as lattice concentration because the volume of impure grain boundary is too small to contain a significant fraction of the total impurities. (Calculating from equation (38) in paper $I$ and assuming a grain radius of $1 \mathrm{~mm}$, a grain-boundary thickness of $9 \times 10^{-10} \mathrm{~m}$, and a partition coefficient of 3000 , grain boundaries contain only $0.4 \%$ of the total impurities.) Chemical analyses and grain-size analyses were not performed on the same samples, but variations with depth of both $\mathrm{Cl}^{-}$concentration and grain-size are relatively smooth. We thus interpolated both data sets and compared them at $100 \mathrm{~m}$ intervals to obtain the points represented by solid circles in Figure 3. We also used average values of 
$1 / K_{1}$ and $C_{\ell}$ taken over each of the four isotopic stages of the core discussed by Petit and others (1981) to obtain the starred points in Figure 3. Error bars on $\mathrm{Cl}^{-}$are from Petit and others (1981) and typically are 30\%. Duval and Lorius (1980) reported an error of $15 \%$ in determining grain-size from a section; we have plotted error bars of $20 \%$ on $1 / K_{1}$ to allow for these measurement errors and for errors in interpolation. We have assumed that the time-scale used is exact. In fact, there is some disagreement about the timescale (Bolzan, 1984). Error bars on $1 / K_{1}$ thus should be somewhat longer. We have tested other time-scales in our analysis and found that the linear relation between $1 / K_{1}$ and $C_{\ell}$ does not change, although slope, intercept, and correlation constant of the relation do change slightly.

The regression line in Figure 3 has the sense of slope predicted by theory, with a correlation coefficient of 0.93 . It indicates that

$$
\begin{gathered}
\alpha=7.5 \times 10^{22}\left(\mathrm{~N} \mathrm{~m}^{-2}\right) /\left(\mathrm{m} \mathrm{s}^{-1}\right) \\
M_{\mathrm{i}}(\mathrm{obs})=7.2 \times 10^{-16}\left(\mathrm{~m} \mathrm{~s}^{-1}\right) /\left(\mathrm{N} \mathrm{m}^{-2}\right)
\end{gathered}
$$

where $M_{\mathrm{i}}$ (obs) is the value of the intrinsic mobility calculated from observations.

Two lines of evidence suggest that the value of $\alpha$ obtained here is reasonable. First, Cahn (1962) and Lücke and Detert (1957) provided independent, highly simplified estimates of the impurity-drag effect. Assuming an interaction energy of $8 k T$ between a grain boundary and an impurity dissolved in it, where $k$ is Boltzmann's constant and $T$ is the absolute temperature, these theories predict impurity-drag effects that bracket the value calculated here. The interaction energy $8 k T$ is relatively high but it is consistent with the observed strong partitioning of $\mathrm{NaCl}$ from ice. If other impurities such as $\mathrm{H}_{2} \mathrm{SO}_{4}$ or $\mathrm{HNO}_{3}$ also contribute to the observed impurity drag, then the drag arising from $\mathrm{Cl}^{-}$is somewhat less than calculated here. Secondly, the drag observed here is slightly less than that observed in certain metallurgical systems. An increase in $\mathrm{NaCl}$ from nearly zero to $10^{-7}$ molecular fraction $\left(2 \times 10^{-7}\right.$ if $\mathrm{NaCl}$ ionizes) at a relative temperature of 0.8 at Dome $\mathrm{C}$ reduces the grain-growth rate by a factor of 3 to 4 , and the partition coefficient of $\mathrm{NaCl}$ out of ice during freezing is 300 to 3000 . This compares with an order-of-magnitude decrease in grain-growth rate caused by addition of $2 \times 10^{-7}$ atomic fraction of silver to lead at a relative temperature of 0.8 , where the partition coefficient is 25 (Rutter and Aust, 1960). Although we do not wish to imply that $\mathrm{Pb}-\mathrm{Ag}$ and $\mathrm{H}_{2} \mathrm{O}-\mathrm{NaCl}$ are entirely analogous, the drag effects appear to be similar.

We thus see that the correlation between grain-size and impurity concentration has the form predicted by theory, and that the magnitude of the impurity-drag force required to explain the observations is entirely reasonable. We thus propose that the small grain-sizes observed in Wisconsinan ice from Dome $\mathrm{C}$ occur because of impurity drag. Impurity drag is probably caused by $\mathrm{Na}^{+}$and $\mathrm{Cl}^{-}$but other soluble impurities may also participate. We emphasize that the mere existence of a correlation between impurity concentration and grain-size does not demonstrate causality; similar correlations exist between grain-size and oxygen-isotopic composition, microparticle concentration, and other factors. The case for impurity drag is strengthened, however, by the fact that the impurity-concentration/ grain-growth correlation has the form we expect if impurity concentration controls grain-growth rate, and by the agreement between the impurity-drag force required to cause the observed change in growth rate and the impurity-drag force expected based on the type and concentration of impurities present. Small grain-sizes observed in Wisconsinan ice from other cores may also arise from impurity drag, but we do not have the data in hand to evaluate this. In this context, it must be remembered that if temperatures are warm enough to cause melting of impure grain boundaries, then increasing impurity content may speed grain growth.

In relation to the Dome C core, Petit and others (to be published; reported in Duval, 1984) have shown that there is a strong correlation between grain-growth rate and surface temperature at the time of deposition or some factor correlated with surface temperature. They express this correlation by describing grain growth using an Arrhenius-type activation energy, and dividing this activation energy into climate-independent and climate-dependent parts, but do not present a clear physical explanation of the origin of the climate-dependent activation energy. The soluble-impurity content of ice at Dome $C$ is strongly correlated with climate (Lorius and others, 1984), so impurity drag provides the physical explanation (personal communication from P. Duval, 1984). This is analogous to the analysis of experimental results by Aust and Rutter (1959) and Rutter and Aust (1960), who assumed that grain growth in materials of varying impurity content can be interpreted in terms of an activation energy. They found that the activation energy consists of an intrinsic (pure material) part plus a term that increases with increasing impurity content.

The observed intrinsic mobility for Dome C, $M_{\mathrm{i}}$ (obs), is also of interest. In paper I we noted that the theoretical value of the intrinsic mobility, $M_{\mathrm{i}}(\mathrm{ty})$, is proportional to the diffusivity of water molecules across grain boundaries, $D_{\mathrm{b}}^{\prime}$, which is usually assumed equal to the diffusivity along grain boundaries, $D_{\mathrm{b}}$. Our value of $M_{\mathrm{i}}$ (obs) is more than two orders of magnitude less than $M_{\mathrm{i}}(\mathrm{ty})$ calculated assuming $D_{\mathrm{b}}^{\prime}=D_{\mathrm{b}}$, although it is more than two orders of magnitude greater than $M_{\mathrm{i}}(\mathrm{ty})$ calculated assuming $D_{\mathrm{b}}^{\prime}=D_{\ell}$,
the lattice diffusivity.

We believe that $M_{\mathrm{i}}$ (obs) is less than $M_{\mathrm{i}}(\mathrm{ty})$ calculated assuming $D_{\mathrm{b}}^{\prime}=D_{\mathrm{b}}$ for two reasons. First, drag caused by any impurities that do not vary with $\mathrm{Cl}^{-}$is included in the value of $M_{\mathrm{i}}(\mathrm{obs})$, which is then reduced below the true intrinsic mobility. Almost certainly there are impurities dissolved in Dome $\mathrm{C}$ ice that do not vary with $\mathrm{Cl}^{-}$, possibly including very small concentrations of $\mathrm{N}_{2}$ and $\mathrm{O}_{2}$. Secondly, there are no compelling reasons why $D_{b}^{\prime}$ should equal $D_{\mathrm{b}}$. Particularly in a molecular material in which rotation as well as translation of molecules is required for cross-boundary diffusion, $D_{\mathrm{b}}^{\prime}$ may be significantly less than $D_{\mathrm{b}}$. (The proposal by Jellinek and Gouda $(1969)$, that $D_{\mathrm{b}}^{\prime}$ equals $D_{\mathrm{b}}$ and that $M_{\mathrm{i}}$ (obs) is reduced below $M_{\mathrm{i}}$ (ty) by the diffusing unit being larger than one molecule, does not seem to explain the observations here. They calculated diffusing units of hundreds of molecules and considered this surprisingly large; however, the same analysis here would predict diffusing units of $10^{13}$ molecules, which is implausible.) Our data do not reveal the controls of $M_{\mathrm{i}}$ (obs) at Dome $\mathrm{C}$ but do give the best available estimate of $M_{\mathrm{i}}$ (obs) there; $M_{\mathrm{i}}$ (obs) should vary exponentially with temperature at other sites.

\section{DISCUSSION AND CONCLUSIONS}

We have demonstrated that many observations concerning grain growth in cold glacial ice that is not deforming rapidly are fully explicable in terms of existing grain-growth theories as modified for ice. In ordinary glacial ice, the average cross-sectional area of grains increases linearly with time. Soluble impurities dissolve in ice, segregate to grain boundaries, and reduce boundarymigration rates, even at the low impurity concentrations of the East Antarctic plateau. This slows the increase of grain area but in most cases does not cause deviation from its linear dependence on time. Analysis of data from the Dome $\mathrm{C}$ ice core suggests that the observed decrease in grain-size from Holocene to Wisconsinan ice is caused by the observed increase in concentration of soluble impurities across the same boundary. This mechanism may also apply at other polar sites where similar grain-size decreases and soluble-impurity increases from Holocene to Wisconsinan ice are observed.

Bubbles in ice are less mobile than boundaries, allowing bubble-boundary separation to occur as geometric constraints are satisfied in an interval below the firn-ice transition but reducing grain-growth rates by only about $10 \%$. The high vapor pressure of ice causes rapid growth of intergranular necks in firn and, combined with the cubic dependence of the bubble-drag force on bubble radius, allows migration of intergranular necks with little drag. Grain growth thus is 
nearly unaffected by porosity in both ice and isothermal firn, and the growth rate does not change across the firnice transition.

Microparticles exert a significant effect on grain growth only if present in high concentrations - typically enough to make the ice look dirty. Both microparticle-drag and impurity-drag forces contribute to the small grain-sizes observed in ice layers bearing volcanic ash or dust from the Byrd Station core. Microparticle-drag forces do not contribute significantly to the reduced grain-growth rate of Wisconsinan ice as compared to Holocene ice.

Natural glacial ice provides an excellent test for graingrowth theory on a time-scale $(\approx 10000$ a) that cannot be tested otherwise. The interplay of future observations on glacial ice and theoretical advances should lead to much better understanding of grain growth.

The discussion here suggests a number of studies that are required to verify and extend our conclusions. Most importantly, an ice-core study should be undertaken in which impurity concentrations, microparticle concentrations, bubble sizes, shapes, and abundances, and grain-sizes are measured on the same samples. Comparison of grain-growth rates and impurity concentrations at different polar sites would be useful; however, it must be remembered that growth rate varies exponentially with temperature but only linearly with impurity content, so temperature differences will have larger effects than impurity differences. The location of impurities in natural ice samples should be characterized better to learn the fractionation factors of different impurities to grain boundaries. Further theoretical studies of bubble drag in firn and shallow ice, and studies on the shape of bubbles and necks located on moving grain boundaries would be of interest, as would further laboratory studies on the effect of impurities on grain growth in ice. In short, grain growth in ice provides a fertile field for inquiry.

\section{ACKNOWLEDGEMENTS}

This work was funded in part by the U.S. National Science Foundation under grant DPP-8315777. We thank J.F. Bolzan, R.H. Dott, jr, P. Duval, A.J. Gow, M. Hillert, J.W. Valley, H.F. Wang, and I.M. Whillans for reading early versions of this manuscript, E. Mosley-Thompson for access to unpublished data, and A.N. Mares and S.H. Smith for manuscript preparation. This is contribution No. 433 of the Geophysical and Polar Research Center, University of Wisconsin-Madison.

\section{REFERENCES}

Alley, R.B., and others. 1986. Grain growth in polar ice: I. Theory, by R.B. Alley, J.H. Perepezko, and C.R. Bentley. Journal of Glaciology, Vol. 32, No. 112, p. 415-24.

Aust, K.T., and Rutter, J.W. 1959. Temperature dependence of grain-boundary migration in high-purity lead containing small additions of tin. Transactions of the Metallurgical Society of $A I M E$, Vol. 215, No. 4, p. 820-31.

Blankenship, D.D., and others. 1982. Seismic investigations of the firn-ice structure at Dome C, East Antarctica, by D.D. Blankenship, R.M. Gassett, and C.R. Bentley. Annals of Glaciology, Vol. 3, p. 339.

Bolzan, J.F. 1984. Ice dynamics at Dome C, East Antarctica. Ohio State University. Institute of Polar Studies. Report No. 85.

Cahn, J.W. 1962. The impurity-drag effect in grain boundary motion. Acta Metallurgica, Vol. 10, No. 9, p. 789-98.

Chatterjee, A.K., and Jellinek, H.H.G. 1971. Calculation of grain-boundary thickness in polycrystalline ice of low salinity. Journal of Glaciology, Vol. 10, No. 59, p. 293-97.

Coble, R.L. 1961. Sintering crystalline solids. I. Intermediate and final state diffusion models. Journal of Applied Physics, Vol. 32, No. 5, p. 787-92.

Delmas, R.J., and others. 1982. Gas-derived aerosol in central Antarctic snow and ice: the case of sulphuric and nitric acids, by R.J. Delmas, J.M. Barnola, and $M$. Legrand. Annals of Glaciology, Vol. 3, p. 71-76.
Duval, P. 1985. Grain growth and mechanical behavior of polar ice. Annals of Glaciology, Vol. 6, p. 79-82.

Duval, P., and Lliboutry, L. 1985. Superplasticity owing to grain growth in polar ices. Journal of Glaciology, Vol. 31, No. 107 , p. 60-62.

Duval, P., and Lorius, C. 1980. Crystal size and climatic record down to the last ice age from Antarctic ice. Earth and Planetary Science Letters, Vol. 48, No. 1, p. 59-64.

Gow, A.J. 1968. Bubbles and bubble pressures in Antarctic glacier ice. Journal of Glaciology, Vol. 7, No. 50, p. 167-82.

Gow, A.J. 1970. Deep core studies of the crystal structure and fabrics of Antarctic glacier ice. CRREL Research Report 282.

Gow, A.J. [1975.] Time-temperature dependence of sintering in perennial isothermal snowpacks. [Union Géodésique et Géophysique Internationale. Association Internationale des Sciences Hydrologiques. Commission des Neiges et Glaces.] Symposium. Mécanique de la neige. Actes du colloque de Grindelwald, avril 1974, p. 25-41. (IAHS-AISH Publication No. 114.)

Gow, A.J., and Williamson, T. 1976. Rheological implications of the internal structure and crystal fabrics of the West Antarctic ice sheet as revealed by deep core drilling at Byrd Station. CRREL Report 76-35.

Greskovich, C., and Lay, K.W. 1972. Grain growth in very porous $\mathrm{Al}_{2} \mathrm{O}_{3}$ compacts. Journal of the American Ceramic Society, Vol. 55 , No. 3, p. 142-46.

Gross, G.W., and others. 1975. Concentration dependent solute redistribution at the ice/water phase boundary. II. Experimental investigation, by G.W. Gross, Chen-ho Wu, L. Bryant, and C. McKee. Journal of Chemical Physics, Vol. 62, No. 8, p. 3085-92.

Hellman, P., and Hillert, M. 1975. On the effect of second-phase particles on grain growth. Scandinavian Journal of Metallurgy, Vol. 4, No. 5, p. 211-19.

Hsueh, C.H., and others. 1982. Overview 22: microstructure development during final/intermediate stage sintering. I. Pore/grain boundary separation, by C.H. Hsueh, A.G. Evans, and R.L. Coble. Acta Metallurgica, Vol. 30, No. 7, p. 1269-79.

Jellinek, H.H.G., and Gouda, V.K. 1969. Grain growth in polycrystalline ice. Physica Status Solidi, Vol. 31, No. 1, p. 413-23.

Koerner, R.M., and Fisher, D.A. 1979. Discontinuous flow, ice texture, and dirt content in the basal layers of the Devon Island ice cap. Journal of Glaciology, Vol. 23, No. 89 , p. $209-22$.

Korotkevich, Ye. S., and others. 1978. Rezul'taty izucheniya vertikal'noy struktury lednikovogo pokrova Antarktidy $v$ rayone stantsii Vostok [Results of vertical structure studies of the Antarctic ice sheet near Vostok]. By Ye. S. Korotkevich, V.N. Petrov, N.I. Barkov, L.I. Sukhonosova, D.N. Dmitriyev, and V.G. Portnov. Sovetskaya Antarkticheskaya Ekspeditsiya. Informatsionnyy Byulleten', No. 97, p. 135-48.

Kyle, P., and others. 1982. The volcanic record of Antarctic ice cores: preliminary results and potential for future investigations, by P. Kyle, J. Palais, and R. Delmas. Annals of Glaciology, Vol. 3, p. 172-77.

Lorius, C., and others. 1979. A 30,000-yr isotope climatic record from Antarctic ice, by C. Lorius, L. Merlivat, J. Jouzel, and M. Pourchet. Nature, Vol. 280, No. 5724, p. $644-48$.

Lorius, C., and others. 1984. Late-glacial maximum-Holocene atmospheric and ice-thickness changes from Antarctic ice-core studies, by C. Lorius, D. Raynaud, J.-R. Petit, J. Jouzel, and L. Merlivat. Annals of Glaciology, Vol. 5, p. $88-94$.

Lücke, K., and Detert, K. 1957. A quantitative theory on grain-boundary motion and recrystallization in metals in the presence of impurities. Acta Metallurgica, Vol. 5, No. 11 , p. $628-37$.

Mizuno, Y., and Kuroiwa, D. 1970. Solute segregation in ice observed by autoradiography. Journal of Glaciology, Vol. 9 , No. 55 , p. 117-24.

Nakawo, M. 1974. Ice fabric studies on a $75 \mathrm{~m}$-long core drilled at Mizuho camp, East Antarctica. Antarctic Record, Vol. 50 , p. 29-34. 
Ocampo, J., and Klinger, J. 1983. Proton mobility in the bulk and the surface of hexagonal ice. Journal of Physical Chemistry, Vol. 87, No. 21, p. 4325-28.

Petit, J.-R., and others. 1981. Ice age aerosol content from East Antarctic ice core samples and past wind strength, by J.-R. Petit, M. Briat, and A. Royer. Nature, Vol. 293, No. 5831, p. 391-94.

Pounder, E.R. 1965. The physics of ice. Oxford, etc., Pergamon Press.

Prodi, F., and Nagamoto, C.T. 1971. Chloride segregation along grain boundaries in ice. Journal of Glaciology, Vol. 10, No. 59 , p. 299-308.

Rutter, J.W., and Aust, K.T. 1960. Kinetics of grain boundary migration in high-purity lead containing very small additions of silver and gold. Transactions of the Metallurgical Society of AIME, Vol. 218, No. 4, p. 682-88.
Shaw, G.E. 1979. Considerations on the origin and properties of the Antarctic aerosol. Reviews of Geophysics and Space Physics, Vol. 17, No. 8, p. 1983-98.

Stauffer, B., and Berner, W. 1978. $\mathrm{CO}_{2}$ in natural ice. Journal of Glaciology, Vol. 21, No. 85, p. 291-300.

Thompson, L.G., and others. 1981. Glaciological interpretation of microparticle concentrations from the French 905-m Dome C, Antarctica core, by L.G. Thompson, E. Mosley-Thompson, and J.-R. Petit. [Union Géodésique et Géophysique Internationale. Association Internationale des Sciences Hydrologiques.] Sea level, ice. and climatic change. Proceedings of the symposium held 7-8 December 1979 during the 17th general assembly of the International Union of Geodesy and Geophysics, Canberra, p. 227-34. (IAHS Publication No. 131.)

Weast, R.C. 1973. Handbook of chemistry and physics. 54th edition. Cleveland, $\mathrm{OH}, \mathrm{CRC}$ Press.

Wolff, E.W., and Paren, J.G. 1984. A two-phase model of electrical conduction in polar ice sheets. Journal of Geophysical Research, Vol. 89, No. B11, p. 9433-38. 